\title{
Post-efecto de $0.5 \mathrm{mg} / \mathrm{kg}$ de diazepam sobre la respuesta de sacudirse en la PNF. Ensayo dos
}

Samuel Bautista-Peña ${ }^{1}$ y Estela Pérez Vargas $^{1}$

\section{Introducción}

La investigación con modelos preclínicos empleando animales no humanos ha permitido progresar en el estudio de los procesos conductuales, mecanismos neuroquímicos, neurofisiológicos y neuroconductuales generados por estimulación aversiva. Responder a situaciones adversas lleva a conductas perturbadas que se traducen en distintos cuadros de ansiedad y depresión. Cuando a un organismo se le somete a estimulación aversiva, estimulación novedosa o estresante, se observa generalmente un estado emocional alterado denominado ansiedad. La atenuación de este tipo de reactividad emocional ha llamado el interés de psicólogos, psiquiatras, farmacólogos, neurofarmacólogos, psicofarmacólogos, farmacólogos conductuales y etnofarmacólogos; para estudiarlo se han ideado un buen número de modelos en donde se valora el efecto antiansiedad o ansiolítico de algu-

1 Universidad Nacional Autónoma de México-Facultad de Estudios Superiores Iztacala. 
nos fármacos (Kumar, Bhat y Shah, 2012). "Actualmente, existen diferentes modelos que valoran el efecto de drogas ansiolíticas y que además se emplean en la búsqueda de otros fármacos con un efecto ansiolítico cada vez mejor. Debido a que aproximadamente $20 \%$ de la población puede sufrir de un momento a otro desórdenes de ansiedad, se cree que esta alta prevalencia es uno de los grandes factores del por qué las drogas ansiolíticas como el diazepam son los psicofármacos que se prescriben más comúnmente" (Savića et al., en Bautista-Peña y Pérez, 2013).

Es claro que una mayor comprensión de las relaciones entre la ansiedad, las condiciones que la generan y las drogas que la atenúan son de utilidad para el tratamiento de la ansiedad. En la búsqueda de estas relaciones se han construido situaciones que asemejan condiciones de ansiedad y que a su vez sirven como pruebas de valoración de fármacos ansiolíticos, tal como anteriormente lo hemos expresado en su análisis y marco conceptual para la administración aguda de diazepam en el ensayo uno de la prueba de nado forzado [PNF] (Bautista-Peña y Pérez, 2013).

El diazepam es un fármaco que se ha usado comúnmente como un agente contra la ansiedad, pertenece a la familia de las benzodiacepinas y se encuentra dentro de cuatro derivados de las benzodiacepinas (clorodiacepóxido, diazepam, oxacepam, cloracepato), que con cierta frecuencia se emplean para tratar la ansiedad. Un modelo preclínico que nos proporciona conductas vinculadas con estados emocionales alterados por estimulación aversiva es la prueba de nado forzado (PNF). La PNF ha permitido describir el proceso de alteración emocional relacionado a la respuesta de sacudirse (Bautista y Pérez, 2007).

Con el propósito de observar el efecto del diazepam sobre el proceso de cambio emocional que presenta la respuesta de sacudirse, se realizó una investigación mayor, de la cual presentamos el avance correspondiente al segundo ensayo (E2), para observar el efecto postdosis de $0.5 \mathrm{mg} / \mathrm{kg}$ de diazepam, 24 horas después de su administración aguda. 


\section{Método}

\section{Animales}

Se utilizaron 14 ratas machos Wistar experimentalmente ingenuas, con un peso próximo a $300 \mathrm{~g}$ al comienzo del experimento, provenientes del Bioterio General de la actual FEs-Iztacala, fueron alojadas en un anaquel con cajas-habitación individuales y con acceso libre a agua y comida.

\section{Materiales}

Como recipiente para el agua se usó un bote de plástico con un diámetro superior de $33 \mathrm{~cm}$ e inferior de $28 \mathrm{~cm}$ y una altura de 53 $\mathrm{cm}$, un termómetro para verificar la temperatura del agua, reloj cronómetro digital, regla métrica para medir la columna de agua en el bote (profundidad). Un calentador de agua (cafetera) para mantener el agua a la temperatura deseada (agregando agua caliente). Una caja que se acondicionó como cámara de secado, colocándole dos focos de 100 watts para formar una atmósfera cálida de aproximadamente $32{ }^{\circ} \mathrm{C}$. Una cámara de video Realistic modelo 125 para grabar las sesiones, y una estructura rectangular de acero inoxidable que sirvió de soporte para la videocámara.

\section{Procedimiento}

Se formaron aleatoriamente dos grupos de siete miembros cada uno, grupo control y grupo experimental. El grupo control nunca recibió tratamiento con diazepam. El grupo experimental recibió 24 horas antes del ensayo 2 (E2), una dosis de $0.5 \mathrm{mg} /$ $\mathrm{kg}$ de diazepam que fue inyectado i.p. $30 \mathrm{~min}$ antes del ensayo uno (E1). Los dos grupos fueron sometidos a la prueba de nado forzado en el E2 que duró 15 minutos y fueron registradas las tasas locales de respuesta correspondientes a los 60 segundos que constituyeron cada uno de los minutos, periodo al que se le llamó lapso. 
El E2 se realizó 24 horas después del E1, en el que había sido administrada la dosis de diazepam. Las sesiones fueron grabadas en video, de las que se obtuvieron los registros y posteriormente se registraron las tasas locales para cada uno de los 15 minutos que duraba el E2.

Teniendo arreglado el recipiente con agua, el experimentador sacó a la rata de su caja habitación, activó la cámara de video y depositó a la rata en el agua, iniciándose en ese momento el conteo de los 15 minutos que duró el E2. Ya que había transcurrido el tiempo del ensayo, se sacó a la rata del agua y fue desactivada la cámara de video.

Después de haber estado en el agua, la rata se colocó en la cámara de secado, en donde permaneció un tiempo aproximado de 15 minutos, hasta quedar casi seca de su pelambre, llegado este momento, se regresó a su caja habitación y se devolvió a su anaquel, en donde permaneció con alimentación y agua libres.

\section{Variables}

Variable independiente: postdosis, 24 horas después del ensayo 1 donde se había administrado una dosis aguda de diazepam (0.5 mg/kg por vía i.p. de diazepam para el grupo experimental en el ensayo 1).

Variable dependiente: La respuesta de sacudir la cabeza (sacudirse), que fue definida como el movimiento enérgico de la cabeza de la rata de un lado a otro, que puede o no extenderse a lo largo de su cuerpo.

\section{Resultados}

De los animales, $100 \%$, tanto del grupo control como del grupo postdiazepam $(0.5 \mathrm{mg} / \mathrm{kg})$, presentaron la respuesta de sacudir la cabeza a lo largo de los 15 minutos que duró el Ensayo 2. Los resultados obtenidos del registro de las tasas locales de cada uno de los 15 minutos nos muestran que para el grupo control la 
respuesta de sacudirse, correspondiente al lapso del minuto uno (0-1), tiene la media de respuestas más bajas de todos los 15 lapsos registrados; la media de respuestas aumentó de manera importante en los lapsos 1-2, 2-3, 3-4 y 4-5, siendo este último lapso el que muestra la media de respuesta mayor para el grupo control; a partir del lapso 5-6 se observa un sentido de disminución de la media de respuestas, que va del lapso 5-6 hasta el 13-14 correspondiente al minuto 14; no obstante, en ningún caso los lapsos llegan a la media de respuestas de sacudirse, observada en el lapso 0-1, correspondiente al primer minuto del ensayo 2 para el grupo control.

Los resultados obtenidos del registro de las tasas locales de cada uno de los 15 minutos para el grupo postdosis de diazepam (GPDz 0.5) muestran que la respuesta de sacudirse correspondiente al lapso 0-1 tiene la media de respuestas más bajas de todos los lapsos registrados; la media de respuestas aumentó de manera importante en los lapsos 1-2, 2-3, 3-4 y 4-5, siendo el lapso 4-5 el que muestra la media de respuesta mayor para el grupo postdosis; a partir del lapso 6-7, se observa un sentido de disminución de la media de respuestas; hay variaciones que semejan cierta estabilidad en tanto que fluctúan en ambos sentidos; no obstante, en ningún caso los lapsos llegan a la media de respuesta de sacudirse, observada en el lapso 0-1, correspondiente al primer minuto del ensayo 2 .

Un primer análisis nos muestra que desde el lapso 0-1 hasta el lapso 7-8, el grupo postdosis tuvo medias de respuestas más bajas que el grupo control, relación que se invierte en los lapsos 10-11, 11-12, 12-13, 13-14 y 14-15, donde es el grupo postdosis el que muestra medias mayores al grupo control.

\section{Discusión y conclusión}

Los resultados del efecto postdosis $0.5 \mathrm{mg} / \mathrm{kg}$ de diazepam se vuelven comprensibles, conservando la estrategia analítica y conceptual utilizada en el análisis de la administración aguda del fármaco en el E1, debido a que se sugieren involucrados los 
mismos mecanismos psicobioquímicos (Bautista-Peña y Pérez, 2013). Las fuerzas hostiles y aversivas de la vida diaria se describen como estresantes, es decir, que el estrés malo, también conocido por algunos como distrés, que alude entre otros aspectos a pena, dolor, angustia, zozobra, se genera a través de condiciones adversas de larga duración; la prueba de nado forzado ha permitido asemejar algunas de esas características experimentalmente. Nuestros resultados concuerdan con los encontrados anteriormente para el grupo control, los cuales plantean que la variación observada en la media de respuestas durante el ensayo 2 nos habla del proceso emocional que se genera ante la situación aversiva inescapable que ocasiona la PNF.

Las variaciones en la media de respuestas de sacudir la cabeza observada para el grupo control podrían ser descritas como un proceso que va de una condición de sorpresa, un periodo de gran ansiedad y posteriormente una condición aparentemente estable, pero de estrés, dado que en ninguno de los lapsos la media de la tasa local se regresó a una media de respuestas semejante a las del primer minuto o lapso 0-1; no obstante, se advierten diferencias entre los grupos control y grupo postdosis, este aspecto queda de manifiesto en el hecho de que $60 \%$ de los lapsos del grupo postdosis presentaron una media de respuesta siempre menor que el grupo control, lo que nos sugiere que hay un efecto postdosis del diazepam, observable 24 horas después de una administración aguda de $0.5 \mathrm{mg} / \mathrm{kg}$ I.P., de diazepam. De ser así, nos invita a pensar que es a partir de postdosis tan bajas de diazepam como $0.5 \mathrm{mg} / \mathrm{kg}$ que se inician pequeños cambios en el proceso emocional, describibles a distintos niveles, que pueden ir desde los conductuales hasta el nivel bioquímico en el organismo. El estrés en la rata está relacionado a los cambios en la neurotransmisión del ácido gamma amino-butírico (GABA), y el diazepam tiene un efecto modulador positivo en los receptores GABA-A (Suárez-Roca, Leal, Silva, Pinerua-Shuhaibar y Quintero, 2008). El ácido gamma amino-butírico (GABA) es un gran neurotransmisor inhibitorio en el sistema nervioso central de los mamíferos. Actúa en dos clases de receptores: inotrópico (GABA-A y GABA-C) y metabotrópico (GABA-B). Los receptores GABA-A 
y GABA-c están localizados la mayoría postsinápticamente, están acoplados con los canales de cloro y median la rápida inhibición sináptica. Los receptores GABA-B están acoplados a las proteínas $G$ y forman heterodimero de GABA-B1, de los que existen un gran número de variantes (1a y $1 b$ ), y subunidades GABA-B2, ambos necesarios para que los receptores GABA-B sean funcionalmente activos (Frankowska, Filip y Przegalinski, 2007), y que la farmacocinética del diazepam es observable aun 24 horas después; no obstante, se requiere continuar con el análisis e investigando al respecto.

\section{Referencias}

Bautista, S., y Pérez, E. (2007). Dos clases de respuesta susceptibles de ser observadas en la prueba de nado forzado (PNF) (96-104). En M. Ramírez Guerrero y E. Cortés Vázquez (Coords.), Psicología Salud \& Educación. Avances y perspectivas en América Latina. México: AmAPSI.

Bautista-Peña, S., y Pérez, E. (2013). Valoración del efecto de una dosis baja de diazepam sobre la respuesta de sacudirse en la PNF. Recuperada de http://www.facico-uaemex. $\mathrm{mx} /$ conten/pdf/109.pdf.

Frankowska, M., Filip, M. y Przegalinski, E. (2007). Effects of GABAB Receptor Ligands in Animal Tests of Depression and Anxiety. Pharmacological Reports, 59, 645-655.

Kumar, D., Bhat, Z.A. y Shah, M.Y. (2012). Anti-Anxiety Activity of Successive Extracts of Angelica Archangelica Linn. On The Elevated T-Maze and Forced Swimming Tests in Rats. Journal of Traditional Chinese Medicine, 32(3), 423-429.

Suárez-Roca, H., Leal, L., Silva, J.A., Pinerua-Shuhaibar, L., y Quintero, L. (2008). Reduced GABA Neurotransmission Underlies Hyperalgesia Induced by Repeated Forced Swimming Stress. Behav Brain Res, 89(1), 159-69. doi:10.1016/j. bbr.2007.12.022. 

ARTÍCULOS TEÓRICOS

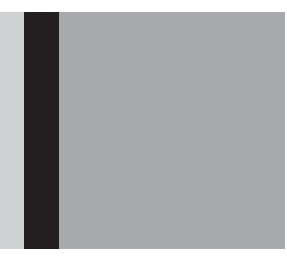


